\title{
DA FILOSOFIA AO DISCURSO: MIKHAIL BAKHTIN
}

\begin{abstract}
Resumo:Mikhail Bakhtin, na primeira metade do século XX, buscou criar uma abordagem filosóficometodológica no estudo da linguagem e da literatura. Em um ensaio conhecido como Para uma filosofia do ato responsável, ele lança os fundamentos filosóficos de todos os demais trabalhos posteriores, construindo assim um caminho que permite pensar o discurso e a linguagem numa perspectiva dialógica. Pretendo, portanto, neste texto, fazer um percurso, resgatando algumas noções filosóficas que dão fundamento para se compreender a noção de discurso na obra de Bakhtin. Não objetivo fazer uma análise de corpus, mas uma trilha teórica para clarear discussões fundamentais aos estudiosos do dialogismo bakhtiniano e a todos os que dialogam com essa perspectiva teórica.
\end{abstract}

Palavras-chave: filosofia do ato; Bakhtin; discurso; dialogismo.

\section{FROM PHILOSOPHY TO DISCOURSE: MIKHAIL BAKHTIN}

\begin{abstract}
Mikhail Bakhtin, in the first half of the 20th century, sought to create a philosophical-methodological approach to the study of language and literature. In an essay known as Toward a Philosophy of the Act, he lays the philosophical foundations of all later works, thus building a path that allows thinking of speech and language in a dialogical perspective. Therefore, intending, in this text, to trace, to rescue some philosophical notions that can help to understand the notion of discourse in Bakhtin's work. It is not an objective to analyze the corpus, but a theoretical path to clarify fundamental discussions for scholars of bakhtinian dialogism and to all those who dialogue with this theoretical perspective.
\end{abstract}

Keywords: philosophy of the act; Bakhtin; discourse; dialogism.

1 Universidade Estadual de Feira de Santana (UEFS), Departamento de Letras e Artes (DLA), Programa de Pós-Graduação em Estudos Linguísticos (PPGEL/UEFS). Professor Assistente de Linguística e Língua Portuguesa. Doutor em Língua e Cultura (PPGLinC/UFBA) e Mestre em Estudo de Linguagens (PPGEL/UNEB). Feira de Santana - Bahia. E-mail: Insilva2@ uefs.br - Lattes: http://lattes.cnpq.br/4295437582484487 - Orcid: https://orcid.org/0000-0001-8642-4397 


\section{INTRODUÇÃO}

Mikhail Bakhtin, no início do século $\mathrm{XX}$, empreende uma empreitada de criar uma abordagem filosófico-metodológica no estudo da linguagem e da literatura. O filósofo russo estava em sintonia com aqueles que viam a filosofia com o papel singular de elaborar métodos adequados com vistas a uma ciência que corresponda à análise da realidade, tal qual fizera Kant (2012, p. 33) ao propor a sua Crítica da razão pura. No Prefácio à Segunda edição da obra, ele afirma: "Ela [a Crítica] é um tratado do método". Ora, tal intento deu à filosofia a missão de oferecer os princípios, as abordagens e os métodos principais para lidar com as questões que surgem nas diferentes esferas da atividade humana; e, por assim dizer, não seria diferente no âmbito da linguagem em que Bakhtin se situa.

A grande questão que ocupa os primeiros anos de reflexão de Bakhtin (2010), compreendidos entre 1919 a 1924, é: em quais condições um pensamento teórico pode ser ético? A resposta a essa questão confronta a perspectiva de que a dimensão ética de um pensamento teórico poder ser deduzida do seu conteúdo universal, chamado por ele de conteúdo-sentido. Essa dedução não é possível, responde-nos Bakhtin em Para uma filosofia do ato responsável. Do conteúdo, só se pode exigir que seja verdadeiro, mas não ético.

Tomar o conteúdo sem levar em conta o processo é um esquartejamento do ato, uma vez que este se constitui de conteúdo e processo, do inteligível e do sensível, do universal e do particular. Portanto, o ato ético, que é de um sujeito situado no espaço e no tempo, é a resposta para a questão. E esse pensamento empreendido lá na filosofia do ato se desenvolve até se aplicar a análise da fala viva, que Bakhtin chamará de discurso, em Problemas da poética de Dostoiévski (2013), o qual é sempre respondente a outros discursos.
Assim, objetivo neste texto fazer um percurso da filosofia do ato até essa noção mais ampla de discurso em Bakhtin ${ }^{2}$, farei isso visando estabelecer uma ponte entre os primeiros anos do pensamento desse pensador russo até o desdobramento da noção, o que ajudará a compreender o fundamento filosófico da perspectiva dialógica bakhtiniana. Ressalto, portanto, que este trabalho não fará análise de enunciados, pois tem uma motivação primordialmente teórica.

\section{A FILOSOFIA DO ATO RESPONSÁVEL E A CRISE CULTURAL}

Entre os anos de 1920 a 1924, Mikhail Bakhtin escrevia, em Vitebsk, o início de seu vasto projeto filosófico, cujo manuscrito só viria a ser revelado após seu retorno do exílio do Cazaquistão nos anos de 1970, quando já estava a salvo das perseguições políticas e após já ser conhecido pela publicação de várias obras de crítica literária. Ainda assim, o texto fragmentário só viria a ser publicado em 1986 com o título "K filosofii postupoka", dado por Sergei Bocharov, já que o autógrafo, além de bastante danificado, não tinha título e lhe faltavam as primeiras oito páginas.

Não apenas nessa obra que se vê que o escrito seria um projeto maior a se desdobrar em vários textos, mas também há razoáveis argumentos de Bénédicte Vauthier (2012), em um interessante artigo dedicado às obras de juventude de Bakhtin, no qual defende haver um tríptico inacabado ligado

2 Nesse sentido, seguirei o posicionamento de compreender como obras de Bakhtin aquelas que não estão em disputa pela autoria, isso por respeitar os autores das edições originais e porque só atribuem a Bakhtin os textos publicados originalmente em seu nome ou os que foram encontrados em seus arquivos. Portanto, quanto ao Marxismo e filosofia da linguagem atribuída a Bakhtin/Volochínov; ao Freudismo e ao $\mathrm{O}$ método formal nos estudos literários, atribuídas a Bakhtin/Medvedev, adota-se aqui a posição de serem dos autores supracitados, os quais foram integrantes do círculo de Bakhtin. Veja detalhes dos demais posicionamentos em discussão em Faraco (2009); e meu posicionamento o fiz em Nascimento (2018). 
à estilística da criação verbal. Nessa hipótese, Vauthier (2012) argumenta que Para uma filosofia do ato responsável viria em primeiro, seguida de $O$ autor e o herói na atividade estética e, por último, O problema do conteúdo, do material e da forma na criação literária. De todo modo, neste momento, interessa-me a primeira parte e é dela de que me ocuparei.

O espanto que a compreensão desse ensaio filosófico inacabado, traduzido para o português como "Para uma filosofia do ato responsável" (2010), pode causar a muitos leitores das obras do Círculo de Bakhtin, sobretudo aos que são mais afeitos a pensadores como Lacan, Foucault, Pêcheux e outros, é que o seu projeto é de uma filosofia moral, "Uma filosofia da vida só pode ser uma filosofia moral", assegurava Bakhtin (2010, p. 117). Isso pode ser verificado tanto pelo conteúdo do escrito quanto pelo fato de Bakhtin se inscrever numa tradição filosófica em que a questão moral está em pauta, além de Dostoiévski, pensador centralmente dedicado a essa questão, ser para ele uma influência paradigmática. Ademais, conta-nos Todorov (1981) um fato curioso: que Bakhtin, para não submergir ao mundo dos conflitos políticos cotidianos, tinha como passatempo favorito passear pelos bosques, lagos e florestas, em Nevel, na companhia de seus amigos Yudina e Pumpianski, ao tom de discussões sobre teologia e filosofias como as de Kant, de Cohen, de Ricket, de Cassirer, filósofos ocupados com a problemática da moral, tanto que Bakhtin e seus companheiros batizaram o seu lago preferido como "Lago da realidade moral".

Tal exemplo ajuda a compreender a preocupação de Bakhtin (2010), nesse escrito, em se centrar na questão da participação singular do sujeito no ser, em que cada ser humano, ao submeter-se às leis gerais de sua espécie, não anula o fato de ser um indivíduo absolutamente único, capaz de imprimir a sua assinatura em cada ato, tornando-se autor, o que faz dele um sujeito moralmente responsável; porquanto o objeto da filosofia moral é essa orientação do ato fundada na sua participação no existir, do contrário a vida não pode ter uma filosofia, assegura Bakhtin (2010).

Assim como muitos outros filósofos do início do século XX, Bakhtin defronta-se com a problemática da crise da cultura, ou mesmo com a crise das ciências humanas; portanto, como pensador, via-se no dever de refletir sobre as questões que a realidade histórico-cultural fazia emergir. Fazendo isso, o pensador depara-se com o nó górdio da crise, o "ato contemporâneo". Tal qual Dostoiévski - em suas obras literárias, sobremaneira em Crime e Castigo, Idiota e em Irmãos Karamázov - fazia pensar sobre as consequências do humanismo, da rejeição dos pressupostos cristãos, que desembocou no niilismo cultural, Bakhtin (2010, p. 115) vê na disjunção entre o motivo do ato e o seu produto, ou seja, na cisão entre o mundo da cultura e o mundo da vida, a fonte dos problemas por que passava não apenas a sociedade russa, mas também a Europa e parte do Ocidente.

Essa cisão entre os mundos é uma das grandes questões teóricas de Bakhtin, não apenas na obra em apreço, mas já se podia observar o problema pulsante no seu primeiro texto publicado Arte e responsabilidade, de 1919, o qual dá motivo para o pontapé inicial de Para uma filosofia do ato responsável. Bocharov (1993, p. XXII - XXIII) escreve, comentando a relação entre ambas as obras na Introdução à edição russa: "Ele [Bakhtin] fala em tom apaixonado sobre superar o velho divórcio entre a arte e a vida através de sua mútua responsabilidade; e essa responsabilidade deveria se realizar na pessoa individual". Embora em ambos os textos os problemas sejam os mesmos, o contexto não o é. Pois no texto de 1919, mesmo não podendo determinar o alcance da discussão pretendida por Bakhtin, pode-se assegurar que ele focaliza a questão a partir do contexto da função 
da responsabilidade na produção e na apreciação artísticas (MARTINS et al., 2012) 3 .

A questão colocada da cisão dos mundos diz respeito ao fato de que um ato-evento real que é sempre realizado por um agente situado bic et nunc, no tempo e no espaço, o qual inclui um processo -, enquanto permanece vivo, é um vir-a-ser. Todavia, ao tornar-se objeto do mundo da teoria, há, por assim dizer, uma transferência, cujo resultado é deixar de ser ato-evento, justo por perder a sua eventicidade e seu vir-a-ser; em outras palavras, perde a sua vocação inclinável para o devir, tornando-se um produto, um vir-a-seracabado. Acontece, como se pode ver, a eliminação do sujeito-agente e sua vitalidade responsável.

Essa objetivação do ato-atividade se dá dentro de uma esfera da atividade humana, seja na arte, na ciência ou na filosofia, cujo resultado é um produto teórico, ou artístico-cultural. No tornar-se produto, há uma "desumanização" do ato ao tornarse conteúdo-sentido, tendo o produto, ou melhor, a cultura se divorciado do ato, desgarrado de sua motivação real; distante de suas raízes ontológicas, esse produto não pode ter outro fim senão a sua deterioração, visto que apenas no mundo da experiência humana é que a verdade viva e singular do ato se afirma e se alimenta. Disso se diz desde as obras teóricas (o que mais tarde ele incluirá especificamente a linguística) e estéticas enquanto produtos até o sistema econômico vigente.

Entretanto, nessa disjunção, não apenas o produto se decompõe, o ato também sofre consequências nocivas, pois perde a sua contrapartida ideal, de maneira que sucumbe ao grau de motivação biológica e econômica

3 Nesse sentido, o contexto heurístico de Para uma filosofia do ato responsável não é apenas maior do que o de Arte e responsabilidade (1919), porém, sobretudo, alcança as questões das mais diversas áreas do conhecimento, incluindo as ciências naturais. Isso porque, como argumentam Martins et al. (2012), a reflexão, que estava limitada à atividade estética, encontra um terreno comum com os discursos científicofilosófico e expositivo-descritivo histórico, para os quais prevalecem a cisão entre o ser real do ato-atividade, ou seja, o mundo da vida, e o seu conteúdo/sentido, o mundo da teoria. elementares. Assim, "a teoria deixa o ato à mercê de uma existência estúpida, exaure-o de todos os componentes ideais e o submete a seu domínio autônomo fechado, empobrece o ato" (BAKHTIN, 2010, p. 116). Há então, de um lado, o sentido objetivo da cultura e, de outro, a subjetividade biológica, que o filósofo chama de ato-necessidade, e cujas marcas deixam na civilização ocidental.

Se o problema da crise da cultura é o "ato contemporâneo", então como construir uma Prima Pbilosophia que compreenda a objetivação sem perder os vínculos com a historicidade? Como fazer isso se não se pode querer corrigir tal situação do interior do produto? A resposta de Bakhtin (2010, p. 115) é: "só se pode resolvê-lo do interior do ato mesmo", em outras palavras, apenas se o produto se juntar ao ato. A resposta à aporia está no ato ético, ou seja, no sujeito responsivo e responsável.

O ato-ético/responsável é a tentativa de superação dessa cisão dos mundos, é o sujeito rejeitando se anular ao se colocar do lado de fora do mundo da vida na contemplação da transcendentalidade do pensamento puro. $\mathrm{O}$ atoresponsável, a contrario, é o adentrar o mundo da vida e deixar-se operar o acento valorativo capaz de fazer acontecer a unicidade em que o sujeito age responsavelmente.

A compreensão de Para uma filosofia do ato responsável, é importante dizer, só pode se dar, razoavelmente, se for comprometida com o caminho metodológico trilhado pelo autor, qual seja, o reconhecimento da cisão entre os mundos e a construção argumentativa com vistas à superação da aporia, já que ele visa destranscendentalizar a ética, a estética e a ciência para refundá-las sobre o sustentáculo das noções de espaço e tempo. Noções essas importantes para mais tarde propor sua translinguística e, portanto, para se compreender as relações dialógicas.

\section{O CENTRO DA UNIDADE}




\section{CONCILIADORA, O SUJEITO}

Bakhtin se insere na discussão filosófica, que perpassa a história da filosofia, ao postular a questão da conciliação entre o universal e o particular como unidade uniocorrente. O filósofo russo se opõe ao monismo, sendo assim, se há na obra um dedo apontado para a manifestação entre o humano e o não-humano, o subjetivo e o objetivo, o tempo e o espaço, o repetível e o irrepetível, o inteligível e o sensível etc., esses opostos são trazidos à luz com o objetivo de mostrar a necessidade da relação unitária. O objetivo, portanto, do filósofo russo é mostrar a disjunção para falar da necessidade de um olhar para a unidade conciliadora, tendo o homem como centro dessa unidade.

No intuito de cumprir tal legado, Bakhtin faz uma crítica pesada ao teoricismo, apontando o dedo em riste ao legado que o racionalismo deixou no pensamento ocidental, cujo resultado é a cisão dos mundos. Diz enfaticamente Bakhtin (2010, p. 81): "Toda a filosofia contemporânea nasceu do racionalismo e está inteiramente impregnada do preconceito do racionalismo [...] segundo o qual somente o que é lógico é claro e racional". A sua resposta heurística a isso, como já dissemos, é a "filosofia da vida". Essa filosofia se filia, de certo modo, à filosofia participativa ${ }^{4}$, como Bakhtin (2010, p. 50-1) mesmo argumenta de que ela é predominante "em todos os grandes sistemas filosóficos". Contrária a essa tendência, a tentativa de um conhecimento teórico não participante, a partir de uma filosofia gnosiológica, teve predomínio quase que exclusivo nos séculos XIX e XX, chegando mesmo a abrandar os termos "existir" e "realidade", fazendo uma despersonalização do pensamento.

4 Que reflete sobre a participação no Ser ou na Comunidade do ser, portanto, uma perspectiva metafísica da realidade. $\mathrm{Ou}$ pode ser compreendida como participação no mundo da vida (lebenswelt).
Porém, a questão em jogo diz respeito às categorias teóricas que não conseguem preservar a realidade dos atos em suas múltiplas dimensões, $a$ fortiori, não é capaz de alcançar as suas irredutíveis singularidades. Por quê? Porque "o ser singular, historicamente real, é maior e mais pesado que o ser uno da ciência teórica" (BAKHTIN, 2010, p. 87). O problema não é que não se pode fazer abstrações do produto ou do processo, como se Bakhtin se opusesse ao fazer teórico, como insinuam equivocamente Bronckart e Bota (2012, p. 300-2), mas a questão está no fato de que nem a abstração do produto nem do processo podem ser tomadas como a totalidade do ato; portanto, a crítica feita por Bakhtin (2010, p. 50) é ao fato de que "o mundo como objeto de conhecimento teórico procura se fazer passar como o mundo como tal, isto é, não só como unidade abstrata, mas também como concretamente único em sua possível totalidade". Fazê-lo, por assim dizer, é incorrer no teoricismo, cujo olhar não vê o diferente, ou, por outro lado, poder-se-ia incorrer no empirismo, que apenas se ocupa do diferente. Logo, onde estaria então a conciliação?

Essa conciliação se dá justamente no ato ético, ou seja, no postupok (ato/feito-façanha) em russo, que é uma ação de um agente intencionado, porquanto situado e não transcendente, que é responsável por aquilo que faz. Assim, o ato responsável, como um Jano bifronte, divindade mitológica romana com duas faces que olha, simultaneamente, para duas direções, está orientado para horizontes opostos, tanto para a singularidade irrepetível quanto para a unidade objetiva, abstrata. Desse modo, o ato, argumenta Bakhtin (2010, p. 43), "deve encontrar uma unidade de uma responsabilidade bidirecional, seja em relação ao seu conteúdo (responsabilidade especial), seja em relação ao existir (responsabilidade moral)".

Vê-se então que o ato é constituído de dois mundos, que fora do evento singular do existir não 
se comunicariam, formando uma unidade única. $\mathrm{E}$ tais mundos põem em questão dois conceitos importantes na arquitetônica bakhtiniana, quais sejam, a verdade universal e a verdade singular; os quais percorrem, é importante que se diga, a história da filosofia.

Istina, em russo, é a palavra empregada para o sentido de verdade universal, de realidade absoluta em oposição ao que é aparente, ilusório, sem permanência. Ela é usada para referir-se à verdade matemática, filosófica, dizendo respeito, portanto, ao conteúdo-sentido de uma teoria, ou mesmo de leis universais e a um universo de possibilidades, como comenta muito bem Amorim (2015, p. 25), “o que se opõe a istina é a ilusão, o que não é real". Mas dessa verdade absoluta e universal não se pode retirar um imperativo categórico para o agir humano, como tenta fazer a ética formal kantiana e neokantiana, visto que esse mundo formalista não tem compromisso com o mundo concreto do ato responsável, por assim dizer, não é mais que o mundo da sua transcrição teórica.

Quanto a isso, Bakhtin (2010, p. 46) argumenta que "Para o dever não é suficiente apenas a veracidade, <é necessário $>\mathrm{o}$ ato de resposta do sujeito, que provém do seu interior", pois do conteúdo válido não se pode tirar o dever, embora este possa estender-se sobre tudo o que é “conteudisticamente" válido. Nesse caso, não existe um dever deduzido do que é em si mesmo lógico, linguístico, estético etc., porque o dever, assegura Bakhtin (2010, p. 47), "é uma categoria original do agir-ato [postuplenie-postupok] (e tudo é um ato meu, inclusive o pensamento e o sentimento)". Por conseguinte, do conteúdo-sentido não se pode dele deduzir o dever, deve-se dele exigir que seja verdadeiro, mas não ético em si mesmo, porque, como argumenta Amorim (2015, p. 22, grifo da autora), "somente o ato de pensar pode ser ético, pois é nele que o sujeito é convocado" a agir responsavelmente.
O dado abstrato, universal, que é em si parcial, deve ser pensado por um sujeito para tornar-se ato. Assim para se falar de um mundo em que a verdade universal se faz unidade com a verdade singular, Bakhtin recorre ao termo russo pravda ${ }^{5}$. Este termo traz em sua carga semântica a ideia de validade e de justiça. Isso quer dizer que "o conhecimento pleno é aquele que, além de verdadeiro, é válido porque é justo. Válido e justo em relação a quê?”, questiona Amorim (2015, p. 22): "Em relação ao contexto do sujeito que pensa, à posição a partir da qual pensa". Portanto, todo ato do pensamento ou criativo é um ato responsável.

Entretanto, para precisar o conceito, é necessário distinguir "ato" de "ação". Esta, traduzida do russo Tat, pode prescindir do pensamento, figurando como algo mecânico e meramente técnico, constituindo-se uma impostura em que por ela o sujeito não assina. Todavia, o ato compreende o pensar, portanto, o agir responsavelmente, dado que Bakhtin está tratando do ato de pensar e de criar como unidades da cultura, ato no qual o sujeito se revela, assina e por ele responde.

$\mathrm{O}$ ato de pensar, pode-se dizer que é uma resposta a uma convocação ética, porque assim como o conteúdo do pensamento teórico obedece a uma necessidade interna de coerência lógica, ele emerge de uma necessidade ética, designado pelo termo nuditel'nost ${ }^{6}$. Para exprimir de maneira adequada o neologismo bakhtiniano e para fazer

5 Amorim (2015, p. 24) cita as indicações de nota da tradutora francesa, G. C. Bardet: “"pravda' é um dos dois termos significando verdade em russo. Em russo moderno, ele se emprega notadamente quando se trata de verdade ligada aos fatos ou da verdade própria a cada um. Antes, essa palavra significou 'direito', 'justiça'. Esse sentido de 'justiça', 'equidade', 'justo', permanece vigorando até o início do século XX, notadamente nos textos filosóficos. Ele subsiste em certos empregos particulares e a título de conotação". Op. cit. BAKHTINE, M. Pour une philosophy de l'acte. Trad. Do russo Ghislaine Capogna Bardet. Lausanne: Editions l'Age d'homme, 2003, p. 18, nota 38.

6 Esse vocábulo, segundo Bardet (2003, p. 119, nota 48), tradutora do russo para o francês, assegura ser um "termo inusitado no russo moderno que significa constrangimento ou obrigação proveniente de uma convicção interior", o que é bem diferente de um constrangimento forçado, porém algo que emana de dentro. 
distinção da palavra nécessité em francês, Bardet propôs o neologismo nécessitance. Em português, Amorim (2015, p. 23) faz um empréstimo do francês, qual seja, necessitância, neologismo que até então dá conta do sentido específico. Em vista disso, "A necessitância de pensar um pensamento ou de a ele aderir é o dever do pensamento, o que se distingue do ser do pensamento" (AMORIM, 2015, p. 23, grifos da autora). E ela diz mais: "O ser do pensamento é dado pelo seu conteúdo e obedece ao princípio de identidade: revela algo que é uno, idêntico a si mesmo e que é indiferente às singularidades dos sujeitos" (AMORIM, 2015, p. 23). Ele é, por assim dizer, um ser possível, por ser universal; todavia, "o dever do pensamento é a adesão irrevogável do sujeito singular que promove assim sua participação no ser” (AMORIM, 2015, p. 23). Mais uma vez, como assegura Bakhtin (2010, p. 46), "Para o dever não é suficiente apenas a veracidade, <é necessário $>$ o ato resposta do sujeito, que provém do seu interior, a ação de reconhecimento da veracidade do dever". Dessa maneira, a unidade se dá justo porque o sujeito situado, coberto de singularidade, o qual pensa um pensamento, confirma sua participação no ser universal $^{7}$ e idêntico ao completá-lo e atualizá-lo justamente com o que não é idêntico nem repetível; o que é o ser real no acontecimento único de pensar o pensamento.

Nessa unidade do ato, há, por assim dizer, uma dialética entre o sensível - designado por Bakhtin

\footnotetext{
7 Embora sejam termos que exprimam realidades semânticas diferentes, é fundamental pontuar que não há uma oposição entre pravda e istina. O "caráter eterno da verdade", argumenta Bakhtin (2010, p. 54), "não pode ser contraposto à nossa temporalidade [dando origem a um aparente paradoxo]", o que se opõe à istina é a ilusão, o que não é real, mas não pravda, como poder-se-ia apressadamente se concluir, pois essa última é o que confere situacionalidade, singularidade e responsabilidade, portanto, realidade a um pensamento. É por ele que o sujeito assina, e tal assinatura diz respeito à posição que ele assume de seu lugar único e insubstituível, no espaço e no tempo, de maneira que "O ato real de cognição não do interior de seu produto teórico-abstrato (isto é, desde o interior de um juízo universalmente válido) mas como ato responsável - incorpora cada significado extra-temporal no existir-evento singular" (BAKHTIN, 2010, p. 55).
}

como dan, em russo, que é o mundo dado - e o inteligível - zadan, que é o mundo postulado -, que é o modo que o filósofo russo encontrou de poder lidar com o ato como um todo. Dessa maneira, o modo como se pode lidar com o ato é por meio da descrição fenomenológica, cuja inspiração vem de Husserl, o qual chamou o método de retorno às "coisas mesmas", ao Lebenswelt, ao mundo vivido. Todavia, importa dizer que enquanto o filósofo alemão permanecia em seu idealismo, Bakhtin foca no aspecto concreto, por conseguinte, contextual e situacional da descrição do ato, o que remete a um sujeito situado, hic et nunc. À vista disso, Bakhtin assegura que "um evento pode ser descrito somente de modo participativo", ou seja, por meio do pensamento participativo, em russo usastnoe myslenie (BAKHTIN, 2010, p. 50). Nesse processo está a base para a noção de discurso em Bakhtin (2013; 2011), em que se distancia de uma descrição abstrata, a qual não leva em conta o sujeito situadamente e suas relações dialógicas. Mas como, então, isso se daria? Precisamos pensar no processo criativo, cuja noção parte da empatia ativa.

\section{DA EMPATIA ATIVA AO SUJEITO SITUADO}

A vahivanie, a empatia ativa, é um conceito imprescindível para arquitetônica de Bakhtin, com uma complexidade filosófica respeitável. Ele se refere ao ato criador de maneira geral e revela-nos a diferença e a tensão entre dois olhares, mas, de certo modo, foi ofuscado pela mais celebrada das contribuições teóricas do filósofo russo, o "diálogo" (WYMAN, 2008, p. 58). Não é à toa que vz̧hivanie é a precursora da noção de relação dialógica, cujos fundamentos já estão presentes em Para uma filosofia do ato responsável e, depois, em $O$ autor e a personagem na atividade estética (1979 [2011]).

O movimento do self em direção ao outro pressupõe uma dicotomia, uma busca e 
uma incompletude. O que o eu busca? Busca complemento, porquanto "para que seja eu, preciso do outro", de maneira que “o 'eu’ é a base da abertura, o 'outro' é a base que assegura a possibilidade de complemento" (CLARK; HOLQUIST, 2004, p. 103). Nessa relação, o eu cria-se, autora-se através dos olhos do outro, porque o meu eu para mim mesmo é invisível, de modo que vivo para o outro e o outro para mim. Eis o movimento de empatia criativa fundado numa filosofia da criação, cujo modelo é o de Deus criando pessoas e pessoas fazendo selves por meio do ato criativo na autoria literária enquanto paradigma para a ação de criar. $\mathrm{Na}$ noção de autoria está, portanto, a verdadeira inventividade ${ }^{8}$ e o tropo da arquitetônica de Bakhtin. Explico em detalhes como isso funciona.

Ora, a vqhivanie diz respeito ao momento inicial em que o sujeito tenta se posicionar do ponto de vista do outro, um deslocar-se para verse pelos olhos do outro, o que só de lá é possível ver. Por isso essa noção oferece uma visão do que é a comunicação interpessoal ideal, proclamando o primado do contato emocional sem cair na fusão com o outro (WYMAN, 2008, p. 58). Esse processo tem, dois momentos, o da identificação, que é a empatia pura e, em seguida, o retorno a si, a objetivação ou abstração9 (BAKHTIN, 2010, p. 61). Para designar esse segundo momento da atividade criativa, Bakhtin lança mão de um neologismo em russo "vnenakhodimost", traduzido como "o fato de ser do lado de fora" ${ }^{10}$, o qual ficou conhecido pelo

8 Não é Bakhtin quem cria essa relação eu/tu. Ela já se fazia presente na filosofia clássica desde o século XVIII, chegando a Bakhtin via os neokantianos de Marburgo, talvez especificamente por Max Scheler. Lá estava Cohen falando da santidade como força que une o homem e Deus, portanto, antes de Buber, ele já meditava na relação self/ outro (CLARK; HOLQUIST, 2004, p. 103). Mas ao focar na autoria, o filósofo russo consegue contribuir de maneira significativa.

9 Todorov assegura que há duas variantes nesse processo: "l'empathie, ou identification (tendance individuelle), et l'abstration, tendance universelle" (1981, p. 153).

10 "le fait de se trouver au-dehors" (TODOROV, 1981, p. 153). termo exotopie ${ }^{11}$, cujas tradução e adaptação foram feitas por Tzvetan Todorov (1981, p. 153), quem primeiro sistematizou o pensamento de Bakhtin para a Europa Ocidental em "Le principe dialogique", de 1981.

Utilizarei o termo exotopia, mas também o termo empatia ativa (vzhivanie), já que este diz respeito a todo o movimento do eu/outro. Desse forma, é muito importante começar tecendo algumas considerações, porque, muito embora Bakhtin não o tenha citado nem em Para uma filosofia do ato, nem em $O$ autor a a personagem na atividade estética, já se sabe que ele manteve um produtivo diálogo ${ }^{12}$ com Max Scheler, o qual é herdeiro do filósofo Franz Brentano (1838-1917), como mostram os trabalhos de pesquisa documental ${ }^{13}$ de Brian Poole (2001) e a pesquisa comparativa de Alina Wyman (2008). Tal pesquisa traça uma comparação conceitual da empatia nas obras de ambos, no entanto, essa relação ainda não é adequadamente explorada ${ }^{14}$, como assegura Wyman (2008, p. 59).

11 Todorov (1981, p. 153) escreve: "et que je traduirai, littéralement encore, mais à l'aide d'une racine grecque, par exotopie". Amorim (2006, p. 95-96) deixa-nos saber que alguns tradutores criticam a tradução de Todorov por sua estranheza ao russo, mas ela julga bastante feliz, pois referese de fato o situar-se em um lugar exterior.

12 O diálogo que estabelecerei com Scheler será mediado por Bakhtin. Recorrei a ele na medida em que for necessário para aprofundar as questões já postas pelo filósofo russo, portanto, ele será um auxiliar na compreensão e no aprofundamento das noções colocadas.

13 O artigo de Brian Poole "From Phenomenology to Dialogue: Max Scheler's Phenomenological Tradition and Mikhail Bakhtin's Development" (2001), parte do livro Bakhtin and Cultural Theory de Ken Hirschkop e David Shepherd, em que o autor se debruça sobre os manuscritos de Bakhtin e mostra a familiaridade do filósofo russo com Scheler, constante em ao menos 56 páginas de excertos do livro de Scheler The Nature of Sympathy, de 1912. Mas o artigo de Poole não trabalha em profundidade a relação complexa entre os conceitos de ambos autores. $\mathrm{O}$ detalhamento dessa pesquisa foi inicialmente apresentado por Poole na VIII International Bakhtin Conferece, na Universidade de Calgary, Canadá, em 1997, cujo título foi "Bakhtin's Early Philosophical Anthropology and New Archival Material (BRANDIST, 2012).

14 Há dois importantes artigos que traçam a relação, um de Vladimir Nikiforov "First Philosophy as Philosophy of Individual Postupok" (2001), mostrando a opção de Bakhtin pelo ato e não pela noção de pessoa. Além desse, há outro artigo de Brian Poole "From Phenomenology to Dialogue: Max Scheler's Phenomenological Tradition and Mikhail Bakhtin's Development" (2001), parte do livro Bakhtin and Cultural Theory de Ken Hirschkop e David Shepherd, em 
Em Bakhtin, a noção aparece em Para uma filosofia do ato em que ele foca a questão da intersubjetividade e, mais tarde, aparece em Autor e a personagem, em que "a tarefa do autor, cujo papel é mais do que estreitamente artístico, é completar o indivíduo (personagem) de fora, elevando a pessoa acima do curso da consciência comunal e concedendo-lhe a dádiva da completude (zavershennost)" (BRANDIST, 2012, p. 14). Ocorre que Bakhtin (2011) aplica a fenomenologia "personalista" de Scheler à noção de autoria, o que "revela uma preocupação com a elevação do indivíduo acima do todo social que será mais tarde traduzida em termos históricos" (BRANDIST, 2012, p. 15) ${ }^{15}$. Essa perspectiva resulta em pensar o sujeito responsivo, responsável e situado.

"Os sujeitos existem no ser real da história, transitivo e aberto em sua eventicidade" (MARTINS et al., 2012, p. 134, itálico dos autores). Isso porque dentro da contemplação estética ou da cognição teórica não se vive, não há vida, portanto lá não há sujeitos, apenas objetos, produtos. Essa qualidade de transitividade do sujeito - que não diz respeito transitoriedade, mas processualidade - é importante porque é fundamento básico para a compreensão da arquitetônica bakhtiniana.

O sujeito é, por assim dizer, na filosofia do ato responsável, um agente dotado da capacidade

que o autor se debruça sobre os manuscritos de Bakhtin e mostra a familiaridade do filósofo russo com Scheler, constante em ao menos 56 páginas de excertos do livro de Scheler The Nature of Sympathy, de 1912. Mas o artigo de Poole não trabalha em profundidade a relação complexa entre os conceitos de ambos autores.

15 Nessa relação entre os filósofos, o que me interessa aqui é a noção de Vzhivanie (empatia ativa), que é literalmente, como diz-nos Alina Wyman, "living into' another self" (Viver em outro eu). Assim, a noção de Vzhivanie de Bakhtin, que é esse movimento feito em direção à consciência do outro, sem no entanto o sujeito perder o excedente produtivo de seu lugar no mundo, tem uma relação frutífera com a noção de empatia ativa (Mitgefühl) de Max Scheler (1942), proposta em Wesen und Formen der Sympathie ("Essência e forma da simpatia"). Dessa maneira, ambos os pensadores trabalham sob a perspectiva de uma empatia ativa, cujo resultado mostra-nos que ao invés de ser uma fusão entre as consciências, como era comum os filósofos contemporâneos de ambos proporem, tem-se uma compreensão ativa do sujeito, em que há uma soberania do empatizar, de maneira que a individualidade não se dissolve no processo empático. de realizar atos concretos, o que significa dizer que ele não é transcendental, despersonalizado, extra-histórico ou extrassocial, a contrario, é situado historicamente, cuja participação se dá ao agir responsavelmente e ao realizar práticas sociais, organizadas por esferas de atividade, as quais pressupõem a relação intersubjetiva e o aqui e o agora, o que mais tarde Bakhtin chamaria de cronotopo.

Nesse sentido, o sujeito é tanto um eu para-si, condição de formação de sua identidade subjetiva, quanto um eu para-o-outro, condição necessária para inserção de sua identidade no plano relacional; portanto responsivo e responsável. Tal constatação permite dizer que o outro é condição para o sujeito, de igual modo, o eu define também o outro. Nisso está o fato de o self não poder ter uma visão completa de si de dentro, mas apenas pelos olhos do outro.

A implicação que essa noção de sujeito traz é a de que este não pode alegar assujeitamento às regras gerais sem passar por sua apreciação, ele não tem desculpa para dizer-se vítima, exceto em circunstâncias de coação. Ou seja, "as relações entre sujeitos não submetem os sujeitos, singulares, ao coletivo de sujeitos, despersonalizando-os, e ao mesmo tempo não atribui a cada sujeito a possibilidade de se sobrepor ao coletivo, tornandose autárquico" (SOBRAL, 2008, p. 229).

De toda forma, o que há é um sujeito agente situado que realiza atos concretos, e, por serem sempre atualizáveis, estão em processo, cujo resultado é um produto (conteúdo-sentido). Nessa perspectiva, a dialética dialógica produto-processo diz respeito ao fato de que o ato pode ser, enquanto produto, objeto de uma generalização, todavia seu processo, enquanto único e irrepetível, não pode ser objeto de generalização. Assim, o ato de um sujeito é um ato de uma autoconsciência situada. 


\section{DA CONSCIÊNCIA AO DISCURSO: OS VALORES}

Ainda, num tom filosófico, é pertinente mostrar como se dá a saída que Bakhtin faz do ato na consciência do sujeito até a sua manifestação discursiva. Para tanto, importa lembrar que é próprio do ser humano responder a valores, diferente dos animais que respondem a estímulos bioquímicos. Isso diz que cada um responde aos valores de um centro valorativo subjetivo que inclui tempo e espaço e orienta os sentidos. Quanto a isso, Bakhtin argumenta:

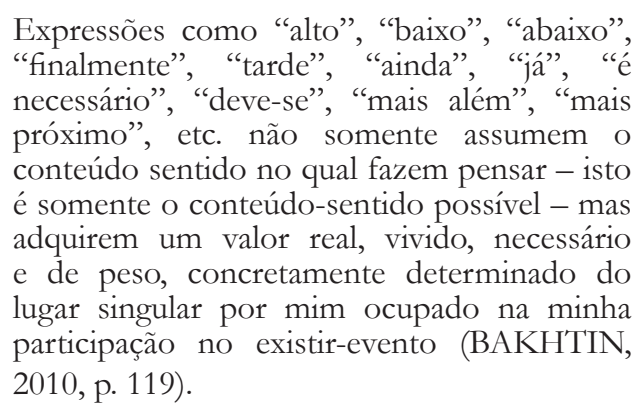

Nisso se encontra a base de como o sentido se atualiza. E, embora Bakhtin não tenha discorrido sobre questões linguísticas específicas, o problema do sentido já estava fortemente presente na Filosofia do ato. A questão colocada é justamente o fato de que existem valores como entidades abstratas e eternas, os a priori de Husserl e Scheler, mas é o sujeito que atualiza seu sentido: "a eternidade do sentido, fora de sua realização, é somente uma eternidade possível privada de valor, insignificante", enfatiza Bakhtin com um grifo (2010, p. 120). Assim sendo, é na encarnação que o conteúdosentido significa: "a eternidade do sentido adquire um valor real, torna-se significativa" (2010, p. 120), torna-se concreta.

Para Bakhtin e seu Círculo, a significação dos enunciados, como constata Faraco (2009, p. 47), "tem sempre uma dimensão avaliativa, expressa sempre um posicionamento social valorativo".
Nesse sentido, todo enunciado é ideológico, como diria Volochínov (VOLÓCHINOV, 2018). O que Bakhtin e seu Círculo colocam em cena é a axiologia como condição de possibilidade dos sentidos da linguagem humana (DIONÍSIO, 2010; 2011).

A contraposição concreta entre o eu e o outro é, para Bakhtin (2010, p. 142), o princípio arquitetônico supremo do mundo. "O mesmo mundo, quando correlacionado comigo ou com o outro, recebe valores diferentes, é determinado por diferentes quadros axiológicos" (FARACO, 2009, p. 21). Então, os valores abstratos (universais) devem ser reconhecidos para que eles façam sentido ao sujeito de seu lugar único (BAKHTIN, 2010, p. 107).

Em "Para uma filosofia do ato responsável", a relação entre o eu e outro não tem uma elaboração específica no âmbito da linguagem. Ela permanece como "uma espécie de metafísica da interação" (FARACO, 2009, p. 73) e cujos contornos vão passar a receber a partir de 1924 [1923] em "O problema do conteúdo, do material e da forma na arte verbap'16, e, em 1926, na chamada de virada linguística do Círculo. Ocasião em que o enunciador passa a ser compreendido como um complexo de posições sociais avaliativas e não apenas como um ser empírico.

Essas vozes aparecem sob análise em Problemas da poética de Dostoiévski (1929), obra na qual Bakhtin (2013) argumenta em favor da tese de que Dostoiévski é o criador de um gênero de romance novo, o polifônico. Desse modo, ele interpela as obras de arte romanescas, fazendo seu caminho da estética à facticidade da vida, buscando acessar a complexidade da linguagem do cotidiano, que, afinal, são os elementos de que é feita a poética dostoievskiana.

$16 \mathrm{O}$ texto é um dos poucos finalizados por Bakhtin. Ele foi provavelmente escrito em 1923, enviado para publicação à revista Russkii Sovremennik, mas por ter sido fechado o texto só foi publicado em 1975, ano da morte de Bakhtin, na coletânea de seu trabalho, Voprosy literatury i estetiki (FARACO, 2015, p. 95). 
As relações dialógicas descritas em Problemas da Poética de Dostoiévski sem a noção de valor não podem existir. Os termos utilizados para ele é juízo (de valor), "posicionamento", "posição de um autor" e "posição semântica". Logo, a relação dialógica é a manifestação na linguagem de um posicionamento de um sujeito em relação ao outro. Em termos mais gerais, como coloca Dionísio (2011, p. 178), "toda vez que ocorre um juízo de valor e conseqüente realização na linguagem definindo uma posição autoral frente à outra posição autoral-valorativa, a relação dialógica se instaura".

Nessa obra, ao colocar em questão a poética do grande literato russo, Bakhtin vai além da estética e postula um problema filosófico mais fundo, qual seja, um problema ontológico ${ }^{17}$. Mas no sentido em que essa palavra se refere à pergunta pelo "o que há", e na estética de Dostoiévski, o que há é diálogo. No entanto, pode-se dizer mais, pois, para Bakhtin (2013, p. 223), o que há é o diálogo inconcluso, porque, como ele mesmo afirma: "ser é comunicar-se pelo diálogo. Quando termina o diálogo tudo termina". Assim, como comenta Hebeche (2010, p.10): “'o que há' não é uma coisa, um sujeito, um construto, uma lei, um princípio, uma concepção do mundo, mas apenas o caráter de estar-em-aberto do diálogo entre as mais variadas idéias".

Ao fazer uma dura crítica à filosofia moderna, que vai de Descartes a Kant, com a noção de sujeito como princípio da unidade do mundo, em que o mundo se converteu para o sujeito em imagem ou representação, Bakhtin faz uma crítica ao princípio monístico, visto que o princípio da unidade do ser se torna em princípio da unidade da consciência (BAKHTIN, 2013, p. 89). Assim, nas primeiras

17 Para Hebeche (2010) é ontológico, embora a ontologia tradicional seja monológica, mas se não tomá-la perspectiva numa perspectiva tradicional a atribuição a uma questão ontológica é válida, assim como o foi em Heidegger e em Nietzsche, pois nem toda ontologia é metafísica, embora, em Bakhtin, ela tenha o pé na metafísica. obras de Bakhtin, há uma crítica a esse modelo da consciência, desdobrando-se em Problemas da Poética de Dostoiévski quando, como argumenta Hebeche (2010, p. 14): “no final, ao invés dos termos 'consciência' e 'autoconsciência' passa-se a empregar de modo mais consistente a noção de discurso, ou melhor, da concepção que entende o discurso a partir da consciência à concepção que toma a consciência como discurso".

Dessa forma, Bakhtin considera, ao comentar sobre Dostoiévski-artista, que a ideia é interindividual e intersubjetiva, de maneira que a dimensão de sua existência não é a consciência individual, todavia, a comunicação dialogada entre as consciências. Assim, a consciência não é uma formação individual subjetiva, e sim "um acontecimento vivo que irrompe no ponto de contato dialogado entre duas ou várias consciências. Nesse sentido, a ideia é semelhante ao discurso, com o qual forma uma unidade dialética" (BAKHTIN, 2013, p. 98, itálico do autor). Dado isso, está posta a passagem do ponto monológico da consciência para a esfera polifônica do discurso em Dostoiévski, porque, como assegura Bakhtin (2013, p. 98), "como discurso, a ideia quer ser ouvida, entendida e 'respondida' por outras vozes e de outras posições" ${ }^{\prime 18}$.

O romance polifônico é a recriação da natureza polifônica da própria vida, pois se coloca "como autocompreensão da força dos discursos que constituem a 'nossa complicada forma de vida', antes da sua abstração pelo discurso objetivador" (HEBECHE, 2010, p. 104). É nessa perspectiva, cujo fundamento está em sua filosofia do ato, que 18 Há quem diga que a passagem da consciência para a linguagem não é uma questão de todo resolvida filosoficamente em Bakhtin; ou melhor, a relação entre as vozes das consciências e o discurso por onde elas acham passagem (HECHECHE, 2010). Embora, o mesmo Hebeche (2010), que ressoa a questão de que a relação entre metafísica e linguagem não está, nitidamente, resolvida em Bakhtin, não desmerece o avanço e as contribuições bakhtinianas para fazer ver as relações dialógicas e possibilitar, por meio de Problemas da poética de Dostoiévski, uma poética da escuta das muitas vozes contra a escuta de uma única voz dos romances monológicos. 
Bakhtin faz a crítica de se tentar dissecar o cadáver da linguagem deixando escapar a sua vitalidade, ou seja, uma crítica do estudo do conteúdo desprezando o seu processo.

O objetivo do estudo de Bakhtin (2013, p. 207) é "o discurso [slovo], ou seja, a língua em sua integridade concreta e viva, e não a língua como objeto específico da linguística, obtido por meio de uma abstração absolutamente legítima e necessária de alguns aspectos da vida concreta do discurso”. Para tanto, sem desprezar a linguística, ele mostra que é preciso ir além dela; atualmente, fala-se em Análise do discurso, todavia o filósofo russo falava em metalinguística, ou como prefere alguns, a exemplo de Faraco (2009), falava-se em translinguística. Bakhtin, em Problemas da poética de Dostoievski (2013, p. 207), assegura categoricamente que "as pesquisas metalinguísticas, evidentemente, não podem ignorar a linguística e devem aplicar os seus resultados". Isso porque "a linguística e a metalinguística estudam um mesmo fenômeno concreto, muito complexo e multifacetado - o discurso $^{19}$ [slovo/palavra] -, porém estudam sob diferentes aspectos e diferentes ângulos de visão". Por ser assim, elas não devem se fundir, mas se completarem mutuamente.

Nesse sentido, vê-se a necessidade de outra ciência que não se detenha apenas sob o objeto sentença - o que seria apenas olhar para o conteúdo-sentido-, cujas relações remetem aos elementos linguísticos abstratos, mas que crie o objeto enunciado, e todo enunciado responde a outro enunciado em suas relações dialógicas (BAKHTIN, 2011; 2013). Ora, a necessidade dessa

19 O termo slovo, que é traduzido por discurso, é retraduzido para o francês com o neologismo Mot [Palavra], em maiúsculo, por Sériot e Tylkowski-Ageeva (2010). Isso porque discurso em Bakhtin em nada tem a ver com o sentido compartilhado por Pêcheux. Sériot (2015, p. 14) esclarece: "Em Bakhtin e Volosinov, o objeto posto em cena com tanta insistência não é o discurso no sentido de Pêcheux, definido em geral como um conjunto de enunciados que 'circulam' sem que sua fonte possa ser estabelecida ou atribuída, que podem pertencer a campos diferentes, mas que obedecem, apesar de tudo, a regras comuns de funcionamento". nova ciência foi anunciada por Bakhtin, no entanto, não se pode dizer que ele a criou formalmente, pois, como argumenta Faraco (2009, p. 105), "ele não recorta um 'objeto calculável', nem formula proposições formais de método", todavia oferece uma contribuição bastante significativa, porque propõe uma arquitetônica filosófica voltada à linguagem capaz de ancorar essa nova ciência, a qual condiz com os objetivos do que se chama hoje de análise dialógica do discurso (BRAIT, 2006) e, no âmbito da retórica argumentativa, tenho chamado de análise dialógica da argumentação (NASCIMENTO, 2018; 2019).

\section{CONCLUSÃO}

A compreensão de como se dá o percurso de Bakhtin de uma filosofia do ato responsável ao discurso serve para deixar um pouco mais claros os fundamentos filosóficos dos estudos dialógicos. Ajuda-nos também a compreender, mais nitidamente, que a linguagem, em termos bakhtinianos, não é menos que a forma fundamental de interação do eu com o outro, cuja realidade essencial é a interação verbal, a qual se dá de maneira situada social e historicamente, pois, afinal, essa interação é uma construção de sujeitos situados, responsivos e responsáveis.

Bakhtin (2010), mesmo não tendo elaborado um conceito sistematizado de linguagem, sobretudo nas obras de juventude, em Para uma filosofia do ato responsável já está nítida que a linguagem é muito mais adequada para exprimir os atos responsáveis do que revelar o aspecto lógico abstrato do mundo teórico. Ou seja, a linguagem aponta para o discurso vivo, o homem falando em um dado espaço e tempo. Portanto, o dialogismo é, nesse sentido, um incessante diálogo, que envolve acordos e desacordos profundos, entre distintos discursos que constituem uma cultura, uma sociedade ou grupo de pessoas. E a análise desse discurso se dá por 
meio de enunciados concretos, produzidos dentro de certos gêneros do discurso, os quais alimentam e retroalimentam discursivamente a vida, a arte, a ciência e a cultura.

\section{REFERÊNCIAS}

AMORIM, M. Para uma filosofia do ato válido e inserido no contexto. In: BRAIT, B. Bakhtin, dialogismo e polifonia. São Paulo: Contexto, 2015.

BAKHTIN, M. Estética da criação verbal. São Paulo: Martins Fontes, 2011.

BAKHTIN, M. Para uma filosofia do ato responsável. São Carlos: Pedro \& João editores, 2010.

BAKHTIN, M. Problemas da poética de Dostoiévski. Rio de Janeiro: Forense Universitária, 2013.

BAKHTINE, M. Pour une philosophie de l'acte. Trad. do russo Ghislaine Capogna Bardet. Lausanne: Editions l'Age d'Homme, 2003.

BOCHAROV, S. G. Introdução à edição russa. In: BAKHTIN, M. Para uma filosofia do ato. Trad. Carlos Alberto Faraco e Cristovão Tezza da edição americana Toward a philosophy of the act. Austin: University of Texas Press,1993. (tradução destinada exclusivamente para uso didático e acadêmico).

BRAIT, B. Bakhtin: outros conceitos-chave. São Paulo: Contexto, 2006.

BRANDIST, C. Repensando o Círculo de Bakhtin: novas perspectivas na história intelectual. São Paulo: Contexto, 2012.

BRONCKART, P-J.; BOTA, C. Bakhtin desmascarado: história de um mentiroso, de uma fraude, de um delírio coletivo. São Paulo: Parábola, 2012.

CLARK, K.; HOLQUIST, M. Mikhail Bakhtin. São Paulo: Perspectiva, 2004.
DIONÍSIO, M., T. A questão do valor na linguagem para (o Círculo) de Bakhtin. (Dissertação de mestrado). Programa de Pós- Graduação em Estudos Linguísticos, do Centro de Ciências Humanas e Naturais da Universidade Federal do Espírito Santo, 2010.

DIONÍSIO, M., T. A questão do valor na linguagem para (o Círculo de) Bakhtin. Percursos Linguísticos: Vitória (ES), v. 3, n. 1, p. 171-182, 2011.

FARACO, C. A. Linguagem \& diálogo: as ideias linguísticas do Círculo de Bakhtin. São Paulo: Parábola, 2009.

HEBECHE, L. Da consciência ao discurso: ensaio sobre Mikhail Bakhtin. Florianópolis: Nefipoline, 2010.

HUSSERL, E. A Ideia da Fenomenologia. Lisboa: Edições 70, 1986.

KANT, I. Crítica da razão pura. Petrópolis: Vozes, 2012.

MARTINS, E. S.; LEITE, F. F.; PONTES, N. C. Dois problemas decisivos sobre "Para uma filosofia do ato": o mundo cindido e os atributos do Ser e do ato ético. Bakhtiniana, São Paulo, 7 (2): 123-141, Jul./Dez. 2012.

NASCIMENTO, Silva, Lucas. Análise dialógica da argumentação: a polêmica entre afetivossexuais reformistas e cristãos tradicionalistas no espaço político. 2018. 557f. (Doutorado em Língua e Cultura) - Instituto de Letras, Programa de PósGraduação em Língua e Cultura, Universidade Federal da Bahia, Salvador, 2018.

NASCIMENTO, Silva, Lucas. Análise dialógica da argumentação polêmica: uma hipótese geral. Entrepalavras, Fortaleza, v. 9, n. 1, p. 151-169, janabr/2019.

POOLE, Brian. From Phenomenology to Dialogue: Max Scheler's Phenomenological Tradition and Mikhail Bakhtin's Development. In: HIRSCHKOP, Ken; SHEPHERD, David. Bakhtin and Cultural Theory. Manchester/UK: Manchester University Press, 2001. 
SCHELER, M. Esencia y forma de la simpatia. Buenos Aires: Editorial Losada, 1942.

SCHELER, M. Ética: nuevo ensaio de fundamentación de un personalismo ético. Madrid: Caparrós Editores, 2001.

SOBRAL, A. U. Ato "responsível", ou ato ético, em Bakhtin, e a centralidade do agente. Signum: Estud. Ling., Londrina, n. 11/1, p. 219-235, jul. 2008.

TODOROV, T. Mikhail Bakhtine: le príncipe dialogique. Paris: Éditions du Seuil, 1981.

VAUTHIER, B. Ler Medvedev para melhor compreender Bakhtin: a relação entre pensamento e linguagem na obra de juventude de Bakhtin. (tradução de Francisco Leite e Edson Soares Martins). Macabéa - Revista Eletrônica do Netlli | V.1., N.2., DEZ. 2012, p. 423-452.

VOLÓCHINOV, V. Marxismo e filosofia da linguagem (Círculo de Bakhtin). São Paulo: Editora 34, 2018.

WYMAN, A. Bakhtin and Scheler: Toward a Theory of Active Understanding. The Slavonic and East European Review, Vol. 86, No. 1 Jan., 2008.

Submissão: junho de 2020 .

Aceite: dezembro de 2020 . 